\title{
SALMONELLA INFECTIONS ASSOCIATED WITH REPTILES: THE CURRENT SITUATION IN EUROPE
}

\author{
Editorial team (eurosurveillance@ecdc.europa.eu) ${ }^{1}$, S Bertrand ${ }^{2}$, R Rimhanen-Finne ${ }^{3}, \mathrm{~F} \mathrm{X} \mathrm{Weill}{ }^{4}$, W Rabsch $^{5}$, L Thornton ${ }^{6}$, \\ J Perevoscikovs ${ }^{7}$, W van Pelt ${ }^{8}$, M Heck $^{8}$ \\ 1. Eurosurveillance, European Centre for Disease Prevention and Control, Stockholm, Sweden \\ 2. National Reference Centre for Salmonella and Shigella, Bacteriology division, Scientific Institute of Public Health, Brussels, \\ Belgium \\ 3. National Public Health Institute, Department of Infectious Disease Epidemiology and Control, Helsinki, Finland \\ 4. National Reference laboratory of Salmonella, Institut Pasteur, Paris, France \\ 5. Robert Koch Institut, Wernigerode Branch, National Reference Centre for Salmonellae and other Enterics, Wernigerode, Germany \\ 6. Health Protection Surveillance Centre, Dublin, Ireland \\ 7. Department of Epidemiological Surveillance of Infectious Diseases, State Agency "Public Health Agency", Riga, Latvia \\ 8. Centre for Infectious Disease Control, National Institute for Public Health and the Environment (RIVM), Bilthoven, The Netherlands
}

\begin{abstract}
Salmonella infections are caused by consumption of contaminated food, person-to-person transmission, waterborne transmission and numerous environmental and animal exposures. Specifically, reptiles and other cold blooded animals (often referred to as "exotic pets") can act as reservoirs of Salmonella, and cases of infection have been associated with direct or indirect contact with these animals. Approximately 1.4 million human cases of Salmonella infection occur each year in the United States and it has been estimated that 74,000 are a result of exposure to reptiles and amphibians [1]. Regular case reports of reptile-associated salmonellosis in the US are available for the period 1994-2002 [2-4]. Cases of Salmonella infection attributed to direct or indirect contact with reptiles or other exotic pets have been described in a number of European countries, too [5-16] but a more comprehensive overview of the magnitude of this problem in Europe is lacking. In total, 160,649 human cases of salmonellosis were reported in 2006 in the then 25 European Union Member States, Bulgaria, Romania, Iceland, Liechtenstein and Norway [17].
\end{abstract}

\section{Methods}

Following the publication in Eurosurveillance of a recent report on reptile-associated salmonellosis in residents in the south east of Ireland 2005-2007 [16], a quick survey was circulated among our journal's editorial advisors to collect data on the occurrence of such cases in other European countries. We asked whether there have been reported cases of salmonellosis attributed to exposure to reptiles or other exotic pets in their country in the past three years and, if yes, to provide data on the age of cases, animals involved and Salmonella serovars associated. The results of our inquiry do not aspire to being exhaustive. Rather, we hope to inspire further investigations and receive more comments and reports on this topic from other European countries.

\section{Results}

\section{Belgium}

Since 2005, approximately 3,000 to 5,000 human Salmonella infections have been detected annually in Belgium [18]. The majority of these infections are food-borne, but sporadic cases acquired by contact with animals have also been reported.
A case of a four-month-old girl who suffered of septicaemia due to Salmonella enterica serovar Pomona was described in 2007. The source of infection was established to be the family's pet turtle [14].

In April 2008, three cases of infection with S. enterica subspecies arizonae ( $S$. enterica subspecies IIla 41:z4,z23:-), all three associated with exposure to snakes were reported. Two infants, both females, aged one month and two months, and a 57-year-old woman, receiving renal dialysis, were infected. The Belgian Heath Inspectorate investigated the cases and conducted interviews with the adult patient and the parents of the affected children. The three cases were not geographically linked. All patients had only indirect contact with snakes. The snakes had been family pets for three weeks to approximately five years before illness onset. The three isolates were not clonally related as determined by pulsed-field gel electrophoresis and were susceptible to all antibiotics tested.

The two infants recovered without antibiotic treatment. However, the 57-year-old woman was hospitalised and the use of antibiotics was necessary.

\section{Finland}

Annually, from 2,300 to 3,000 cases of salmonellosis are reported to the National Infectious Disease Registry (NIDR) in Finland [19]. Less than $20 \%$ of the cases are considered domestically acquired. During 2005-2008, three cases of salmonellosis (S. enterica serovar Paratyphi B biovar Java 4,5,12:b:1,2, S. enterica serovar Morehead 30:i:1,5 and S. enterica subspecies diarizonae 47:-:-) associated with pet snake were reported: a 50-year-old female, a seven-month-old girl and a 10-month-old boy. None of the cases had previous travel history. The findings above were based on additional information available from laboratory notifications since the suspected source of Salmonella infection is not reportable to NIDR. The Salmonella status of the animals is not known.

In 2005, a family outbreak of $S$. enterica serovar Braenderup $6,7: e, h: e, n, z 15$ associated with a pet turtle was detected. Six cases were identified: four males aged from 11 months to 39 years and 
two females aged six years and 56 years. All cases and the turtle were tested positive for $\mathrm{S}$. Braenderup.

\section{France}

In France, three reptile-associated cases of Salmonella infection were identified in the past three years: two cases in 2005 and one, imported from China, in 2006. The patients were all young children, aged eight months, three years and four years, respectively. They were infected with a multi-resistant strain of $S$. enterica serovar Typhimurium. The first two cases had contact with, respectively, a snake and an iguana; in the third case an indirect link to turtle (consumption of turtle soup) was found. In France, information about exposures at risk of infection is not systematically available through the surveillance system. Exposure information is obtained when an investigation is carried out usually because of the occurrence of a cluster. Therefore, it is likely that the occurrence of reptile-associated cases in France is underestimated.

\section{Germany}

An increasing number of human cases of Salmonella infection associated with reptiles have been reported in Germany in the past three years [20]. The majority of cases were detected retrospectively, after serotyping of the Salmonella strains. According to the standard procedures, in case of an infant infected by $S$. enterica subspecies II-IV the National Reference Laboratory informs the local health authorities about the possibility of transmission of an exotic Salmonella strain from reptile to child. In many such cases subsequent telephone interviews conducted by the local health authorities with the parents of the infected children have revealed direct or indirect contact to reptiles living in the same household.

Although infections in adults with contact to reptiles have been reported, in most cases infants less than one year old were affected. Some children had to be hospitalised. The age of cases and the serovars with antigen formula are shown in Table 1.

The youngest child affected was an eight-week-old female baby with acute haemorrhagic diarrhoea and fever. With symptomatic treatment and breastfeeding, her condition improved without antibiotic therapy. Microbiological analysis and subtyping identified infection with $S$. enterica serovar Pomona. The source of the infection was found to be a bearded dragon (Pogona species) living in a neighbourhood household. Monitoring of the child showed shedding of the bacterium over a nine month period [21].

An investigation of Salmonella infection in five-month-old triplets living with two reptiles in the household revealed that the animals harboured a population of concurrent Salmonella serovars. In the children, S. enterica subspecies I, serovar Apapa was identified. From the reptiles, S. Apapa was isolated along with three other serovars: S. enterica subspecies II 58:c:z6, S. enterica subspecies II 47:d:z39 and S. enterica serovar Tennessee [Robert Koch Institute, Wernigerode Branch, unpublished]. All these serovars are pathogenic to humans.

\section{Ireland}

At least 14 cases of salmonellosis associated with reptile contact have been identified in Ireland over the last three years (Table 2). Six cases in south east Ireland have been described previously [16], information on the remaining cases was obtained by writing to the Directors of Public Health in the eight regions (replies received from two), from searching the national infectious disease system database (Computerised Infectious Disease Reporting - CIDR), and from the National Salmonella Reference Laboratory. It cannot be considered comprehensive but is an indicator that the problem of salmonellosis transmission from pet reptiles is present in Ireland.

\section{Latvia}

In Latvia, there have been no cases of salmonellosis associated with direct or indirect exposure to reptiles during the past three years, except a single case of $S$. enterica serovar Stanley reported earlier this year in a two-year-old child. The source of infection was established to be pet food used for reptiles which the child had often put in his mouth. S. Stanley was isolated from food sample. Other countries were notified about the possibility of pet food contamination through the early warning response system (EWRS). In Latvia, exposure to pet food is now considered to be an additional risk factor of infection in small children and it has to be taken into account during investigation of salmonellosis cases.

\section{The Netherlands}

Salmonellosis is not a notifiable disease in the Netherlands and no information is recorded routinely with regard to the (probable) source of infection. However, the National and European Reference Laboratory (CRL) for Salmonella at the Dutch National Institute for Public Health and the Environment (RIVM) identifies all the isolates sent in from humans (mostly from regional public health laboratories - PHLs) and farm animals, from food, animal food, pet animals and from the environment [22]. Since 1984, this has covered typing results for over 200,000 isolates of 1,143 serovars and phagetypes (of Enteritidis and Typhimurium only). Over 2,200 isolates have been derived from reptiles and amphibians typically sent in by zoos (Table 3). The majority of these isolates were found to belong to the subspecies II (salamae), IIla (arizonae), IIIb (diarizonae), VI (houtenae) and a few to S. bongori (before 1987 , S. subsp. V, now own species) or VI (indica) but a sizable number of specific serovars from subspecies enterica (subspecies l) were identified as well.

Attribution techniques comparable to those used in Denmark $[23,24]$ were used to estimate the fraction of isolates derived from humans that could be accounted for by exposure to reptiles or amphibians, broilers, layers/eggs, pigs, cattle, large explosions, travel or miscellaneous sources. Of 15,146 cases of laboratoryconfirmed salmonellosis sent in by the PHLs $(64 \%$ coverage of the Dutch population) between 2000 and 2007, an estimate of 103 could be associated with reptiles or amphibians, presumably by direct or indirect contact (Figure). While laboratory-confirmed salmonellosis from humans dropped dramatically in the eighties of the past century and gradually decreased afterwards, the absolute number of isolates attributed to exposure to reptiles and amphibians clearly increased in the new millennium although was still $<1 \%$ of all human cases of salmonellosis in 2007. It can be concluded that the importance of Salmonella infections related to reptiles and amphibians in the Netherlands is minor but has increased in recent years.

\section{Other}

We received also responses from Austria, Bulgaria, Estonia, Luxembourg, Malta, Norway, Portugal, Romania and Spain reporting no known human cases of salmonellosis associated with reptiles and other exotic pets. However, often information on this kind of exposure is not available in the notification data. In addition, it is worth noting that in Norway it is forbidden to have reptiles as pets except with a special permit. 
T A B L E 1

Salmonella infections with known exposure to reptiles in Germany from 2006 to date (as of 24 May 2008)

\begin{tabular}{|c|c|c|c|c|}
\hline Year of notification & Gender & Age & Salmonella subspecies, serovar, antigen formula & Associated reptile contact \\
\hline 2006 & $\mathrm{~F}$ & 2 months & Salmonella enterica subspecies IV, 45:g, $\mathrm{z}_{51}:^{-}$ & Bearded dragon \\
\hline 2006 & $\mathrm{~F}$ & 6 months & Salmonella enterica subspecies IV, 48:g, $\mathrm{z}_{51}:-$ (former S. Marina) & Gecko \\
\hline 2006 & $\mathrm{~F}$ & 2 years & Salmonella enterica subspecies II, 50:z: $z_{23}$ & Iguana \\
\hline 2006 & M & 2 months & Salmonella enterica subspecies IV, 50:g, $\mathrm{z}_{51}:-$ & Snake \\
\hline 2006 & M & 1 year & Salmonella enterica subspecies II, 58:c: $\mathrm{z}_{6}$ & Reptile \\
\hline 2006 & M & 42 years & Salmonella enterica subspecies IV, 44:-:- & Reptile \\
\hline 2006 & M & 25 years & Salmonella enterica subspecies IIIb, 47:i: $z_{53}$ & Snake \\
\hline 2006 & $\mathrm{~F}$ & 25 years & Salmonella enterica subspecies IIIb, 50:z: $z_{23}$ & Snake \\
\hline 2006 & M & 3 months & Salmonella enterica subspecies IV, 44: $\mathrm{z}_{4}, \mathrm{z}_{23}:-$ & Snake \\
\hline 2006 & $\mathrm{~F}$ & 8 weeks & Salmonella enterica subspecies I, serovar Pomona 28:y:1,7 & Bearded dragon \\
\hline 2006 & $\mathrm{~F}$ & 8 months & Salmonella enterica subspecies IIIa, $41: \mathrm{z}_{4}, \mathrm{z}_{23}:-$ & Snake \\
\hline 2006 & & $3 \times 5$ months (triplets) & Salmonella enterica subspecies I, serovar Apapa, 45:m,t:- & Bearded dragon \\
\hline 2007 & $\mathrm{~F}$ & 8 months & Salmonella enterica subspecies II, $47: \mathrm{d}: \mathrm{z}_{39}$ & Bearded dragon \\
\hline 2007 & $\mathrm{~F}$ & 24 years & Salmonella enterica subspecies IIIa, $41: \mathrm{z}_{4}, \mathrm{z}_{23}:-$ & Snake \\
\hline 2007 & $\mathrm{~F}$ & 20 years & Salmonella enterica subspecies IV, 45:g, $\mathrm{z}_{51}:-$ & Gecko \\
\hline 2007 & $\mathrm{~F}$ & 29 years & Salmonella enterica subspecies II, 58:-:1,6 & Bearded dragon \\
\hline 2007 & M & 4 months & Salmonella enterica subspecies IV, 44: $\mathrm{z}_{4}, \mathrm{z}_{23}:-$ & Snake \\
\hline 2008 & M & 7 months & 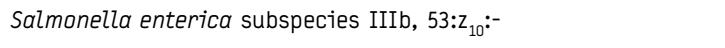 & Snake \\
\hline 2008 & M & 8 months & Salmonella enterica subspecies II, $58: \mathrm{lz}_{13}, \mathrm{z}_{28}: \mathrm{z}_{6}$ & Bearded dragon \\
\hline 2008 & $\mathrm{~F}$ & 16 months & Salmonella enterica subspecies IIIb, 61:l,v:1,5,7 & Snake \\
\hline 2008 & $\mathrm{~F}$ & 42 years & Salmonella enterica subspecies I, serovar Ago 30:z ${ }_{38}:-$ & Bearded dragon \\
\hline 2008 & $\mathrm{~F}$ & 47 years & Salmonella enterica subspecies IV, $44: \mathrm{z}_{4}, \mathrm{z}_{23}:^{-}$ & Bearded dragon \\
\hline 2008 & M & 29 years & Salmonella enterica subspecies IV, 50:r: $\mathrm{z}_{35}$ & Snake \\
\hline 2008 & $\mathrm{~F}$ & 47 years & Salmonella enterica subspecies IIIb, $61: \mathrm{z}_{52}: \mathrm{z}_{53}$ & Snake \\
\hline 2008 & M & 7 months & Salmonella enterica subspecies I, serovar Poona, 13,22:z:1,6 & Snake \\
\hline 2008 & $\mathrm{~F}$ & 11 months & Salmonella enterica subspecies I, serovar Gaminara, 16:d:1,7 & Bearded dragon \\
\hline 2008 & M & 3 years and 9 months & Salmonella enterica subspecies I, serovar Jangwani, 17:a:1,5 & Reptile \\
\hline 2008 & $\mathrm{~F}$ & 8 months & Salmonella enterica subspecies IV, $18: \mathrm{z}_{36} \mathrm{z}_{38}:-$ & Iguana \\
\hline 2008 & $\mathrm{~F}$ & 17 months & Salmonella enterica subspecies I, 28:y:1,7 & Turtle \\
\hline 2008 & M & 8 weeks & Salmonella enterica subspecies II, 35:g,m,s:- & Bearded dragon or chamaeleon \\
\hline 2008 & $\mathrm{~F}$ & 2 months & Salmonella enterica subspecies IV, $44: \mathrm{z}_{4}, \mathrm{z}_{23}:-$ & Snake or bearded dragon \\
\hline
\end{tabular}

Data source: National Reference Centre of Salmonella and other Enterics, Wernigerode, Germany 
T A B L E 2

Salmonella infections with known exposure to reptiles and other exotic pets in Ireland from 2005 to date (as of 16 May 2008)

\begin{tabular}{|c|c|c|c|c|}
\hline $\begin{array}{l}\text { Year of } \\
\text { notification }\end{array}$ & Gender & Age & Organism Description & Associated reptile contact \\
\hline 2005 & M & 11 years & Salmonella enterica subspecies I, serovar Minnesota & Pet iguana \\
\hline 2006 & M & 12 years & Salmonella enterica subspecies I, serovar Monschaui & Pet iguana \\
\hline 2006 & $\mathrm{~F}$ & 15 years & $\begin{array}{l}\text { Salmonella enterica subspecies I, serovar Enteritidis } \\
\text { PT21 }\end{array}$ & Pet terrapin \\
\hline 2006 & M & 6 months & Salmonella enterica subspecies IIIb (diarizonae) & Parents have pet snakes \\
\hline 2007 & M & 4 months & Salmonella enterica subspecies I, serovar Pomona & Contact with Terrapins \\
\hline 2007 & M & 4 weeks & Salmonella enterica subspecies IIIa (arizonae) & Parent has pet snake. Child visited reptile farm with parent \\
\hline 2006 & $\mathrm{~F}$ & 8 months & Salmonella enterica subspecies I, serovar Florida & Reptile owner \\
\hline 2007 & M & 36 years & $\begin{array}{l}\text { Salmonella enterica subspecies I, serovar Paratyphi } \\
\text { B biovar Java }\end{array}$ & Contact with birds and tropical fish \\
\hline 2007 & M & 1 month & Salmonella enterica subspecies I, serovar Stanley & Lizard \\
\hline 2008 & $\mathrm{~F}$ & 3 months & Salmonella enterica subspecies I, serovar Infantis & Turtles in house \\
\hline 2008 & $\mathrm{~F}$ & 9 months & Salmonella enterica subspecies I, serovar Thompson & $\begin{array}{l}\text { Terrapins. Swabs from terrapin tank also positive for } \\
\text { Salmonella Thompson }\end{array}$ \\
\hline 2008 & $\mathrm{~F}$ & 1 month & Salmonella enterica subspecies I, serovar Pomona & Terrapins \\
\hline 2008 & M & 50 years & Salmonella enterica subspecies I, serovar Infantis & Contact with turtles, terrapins, lizards, other reptiles \\
\hline 2008 & $\mathrm{~F}$ & 23 years & Salmonella species & Keeps reptiles and exotic rodents as pets \\
\hline
\end{tabular}

Note: The first six cases were already described in another paper [16]

T A B L E 3

Isolates received and typed at the Netherlands' National Institute for public health and the environment (RIVM) between 1984 and 2007, human cases and reptiles and amphibians

\begin{tabular}{|l|l|l|l|}
\hline \multirow{2}{*}{ S. enterica subspecies } & serovar & human & $\begin{array}{l}\text { reptile/ } \\
\text { amphibian }\end{array}$ \\
\hline \multirow{2}{*}{ enterica (I) } & Typhimurium & 31,602 & 61 \\
\cline { 2 - 4 } & Enteridis & 20,543 & 22 \\
\cline { 2 - 4 } & Typhi & 1,086 & -- \\
\cline { 2 - 4 } & Paratyphi A/B/C & 379 & -- \\
\cline { 2 - 4 } & Other serovars & 22,705 & 848 \\
\hline \multirow{2}{*}{ salamae (II) } & & 32 & 274 \\
\hline arizonae (IIIa) & & 16 & 196 \\
\hline diarizonae (IIIb) & & 33 & 569 \\
\hline houtenae (IV) & & 16 & 289 \\
\hline bongori/indica (V/VI) & & 3 & 3 \\
\hline
\end{tabular}

F I G U R E

Estimated source origin of human cases of salmonellosis in the Netherlands between 2000 and 2007, using attribution analysis of typing data $(n=15,146$ isolates $)$

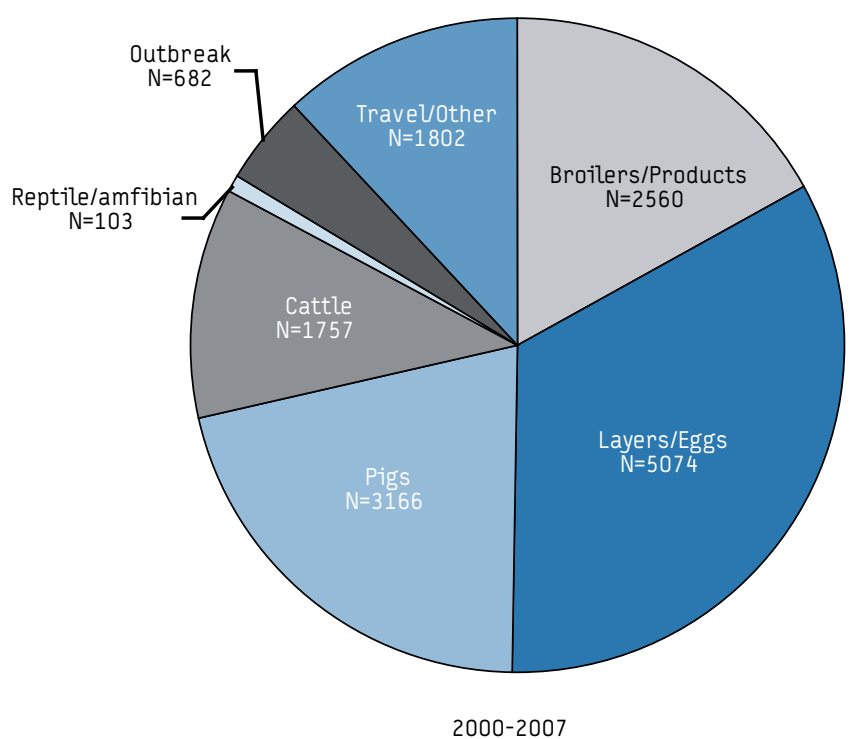

$(15,146$ isolates from human cases) 


\section{Discussion}

Data presented in this paper is far from complete and uniform. Due to differences in surveillance systems, the information on the probable source of Salmonella infection varies greatly across countries, and this is reflected in the above contributions from various countries. For example, in the Netherlands where salmonellosis is not subject to mandatory notification, the estimate of the proportion of cases due to contact with reptiles and amphibians was based on typing results from the national reference laboratory. In most countries, although cases of salmonellosis are reported within the national surveillance system, the source of infection is not routinely given, and the possible exposure to reptiles is usually revealed in the course of additional epidemiological investigation following the results of laboratory testing. The true number of cases due to direct or indirect contact with these animals is thus likely to be underestimated.

The prevalence of infants below one year of age among cases associated with exotic pets may be partly due to the bias in investigating these cases of salmonellosis more thoroughly. Nevertheless, small children should be considered to be at an increased risk of infection, and targeted specifically by recommendations. All the more so, considering evidence of the serious complications including sepsis and meningitis in children who acquired salmonellosis from reptiles $[2-5,14]$.

An important subject not tackled by this paper is the problem of antibiotic resistance. It would be interesting to collect and analyse available data on antibiotic resistance of strains associated with this kind of transmission but such investigation would have surpassed the scope of the present article.

\section{Conclusion}

The present article and earlier publications [5-16] indicate that although known cases attributed to exposure to reptiles and other exotic pets may constitute a small proportion of all human cases of salmonellosis, it is likely to be an underestimated but growing problem that merits more attention. The number of pet reptiles is steadily increasing in some European countries. For example, in Germany in 2007, more than 500,000 reptiles were imported through the airport in Frankfurt am Main [18]. Reptiles are known to shed Salmonella frequently. They are pathogenic to humans and reptile-associated salmonellosis is being recognised as an emerging zoonosis.

Import restrictions and public information campaigns were shown to be effective public health measures against reptile-associated salmonellosis in Sweden [10]. In the US, the Association of Reptilian and Amphibian Veterinarians (ARAV) produced guidelines for reducing the risk of transmission of Salmonella from reptiles to humans, including a client education handout distributed at the points of sale of these animals [25]. Also, the US Centers for Disease Control and Prevention (CDC) published recommendations which include washing hands with soap and water after handling reptiles or their cages and keeping reptiles out of food preparation areas. The CDC also advises that pregnant women and young children should not have reptiles as pets [4].

In Europe recommendations related to the handling of reptiles and other exotic pets exist in the veterinary sector but it appears that agreed guidelines on prevention of salmonellosis transmission from reptiles to humans should be extended to the field of public health, and target health professionals as well as the general public.
The public needs to be made aware of the possibility of acquiring infection from exotic pets, and it is important that physicians and public health experts consider this way of transmission when investigating cases.

\section{Acknowledgements}

We thank Reinhild Strauss (Austria), Mira Kojouharova (Bulgaria), Kuulo Kutsar (Estonia), Robert Hemmer (Luxembourg), Tanya Melillo Fenech (Malta), Karina Junussova (Norway), Judite M. F. Catarino (Portugal), Mircea Popa (Romania) and Luisa P. Sánchez Serrano (Spain) for responding to our survey.

Authors also wish to acknowledge their colleagues in individual countries who conducted investigations and provided detailed data on cases described in this paper:

Belgium: G. Hanquet, D. Baeyens, H. Steenhout, F. De Cooman, J. Griselain, R. Mak, K. De Schrijver, S. Lokietek;

Finland: S. Seppälä, H. Kuronen, K. Mäkisalo;

France: H. de Valk, N. Jourdan-da Silva;

Germany: A. Fruth, M. Wahnfried, S. Kulbe, S. Brockmann

Ireland: P. Garvey, F. Cloak, P. McKeown, M. Cormican, N. De Lappe, C. Ni Shuileabhan, P. Jennings, M. Mahon, 0. O'Reilly;

Latvia: I. Lucenko, A. Brila, S. Magone, G. Dzene;

The Netherlands: H. Maas, A. Verbruggen, D. Notermans.

\section{References}

1. Mermin J, Hutwagner L, Vugia D, Shallow S, Daily P, Bender J et al. Reptiles, amphibians and human Salmonella infection: a population-based, case-control study. Clin Infect Dis. 2004; 15;38 Suppl 3:S253-61.

2. CDC. Reptile-associated salmonellosis - selected states, 1994-1995. MMWR 1995;44:347-50.

3. CDC. Reptile-associated salmonellosis - selected states, 1996-1998. MMWR 1999;48:1009-13.

4. CDC. Reptile-associated salmonellosis - selected states, 1998-2002. MMWR 2003; 52(49):1206-09.

5. Cyriac J, Wozniak ER. Infantile Salmonella meningitis associated with geckokeeping. Commun Dis Public Health. 2000 Mar;3(1):66-7.

6. Ward L. Salmonella perils of pet reptiles. Commun Dis Public Health. 2000;3(1):2-3.

7. Willis C, Wilson T, Greenwood M, Ward L. Pet reptiles associated with a case of salmonellosis in an infant were carrying multiple strains of Salmonella. J Clin Microbiol. 2002 Dec;40(12):4802-3.

8. Stam F, Römkens TE, Hekker TA, Smulders YM. Turtle-associated human salmonellosis. Clin Infect Dis. 2003;37(11):e167-9.

9. Wybo I, Potters D, Plaskie K, Covens L, Collard JM, Lauwers S. Salmonella enterica subspecies houtenae serotype 44:24, z23:--as a rare cause of meningitis. Acta Clin Belg. 2004;59(4):232-4.

10. De Jong B, Andersson Y, Ekdahl K. Effect of regulation and education on reptileassociated salmonellosis. Emerg Infect Dis. 2005;11(3):398-403.

11. Bruins MJ, de Boer AM, Ruijs GJ. [Gastroenteritis caused by Salmonella from pet snakes] Ned Tijdschr Geneeskd. 2006;150(41):2266-9. Dutch.

12. Corrente M, Totaro M, Martella V, Campolo M, Lorusso A, Ricci M, et al. Reptileassociated salmonellosis in man, Italy. Emerg Infect Dis. 2006;12(2):358-9.

13. Berendes TD, Keijman JM, te Velde LF, Oostenbroek RJ. Splenic abscesses caused by a reptile-associated salmonella infection. Dig Surg. 2007;24(5):397-9.

14. Brédart S, Wastelin M, Collard JM, Coppée M, Bodart E. [Pet turtle and septicemia: what is the relationship?] Rev Med Liege. 2007;62(7-8):496-7. French.

15. Hames A, Mumford J, Hale J, Galloway A. Salmonella Michigan soft tissue infection in an immunocompromised child. J Clin Pathol. 2008;61(6):773-4.

16. O'Byrne AM, Mahon M. Reptile-associated salmonellosis in residents in the south east of Ireland 2005 - 2007. Euro Surveill. 2008;13(15):pii=18830. Available from: http://www.eurosurveillance.org/ViewArticle.aspx?ArticleId=18830 
17. The Community Summary Report on Trends and Sources of Zoonoses, Zoonotic Agents, Antimicrobial resistance and Foodborne outbreaks in the European Union in 2006. Available from: http://www.efsa.europa.eu/EFSA/DocumentSet/ Zoon_report_2006_en.pdf

18. National Reference Centre for Salmonella and Shigella. Annual Report on Human Salmonella and Shigella in Belgium 2006, Institute of Public Health. Available from: http://www.bacterio.iph.fgov.be/reporting/reports

19. Infectious Diseases in Finland 2007. Publications of the National Public Health Institute $B 9 / 2008$.

20. Hatt JM, Fruth A, Rabsch W. [Reptile-associated salmonellosis -information update for veterinarians]. Tierärztliche Praxis 2008. in German. (In submission.)

21. Böhme H, Fruth A, Rebmann F, Sontheimer D, Rabsch W. [Reptile-associated salmonellosis in a breastfeed infant] Klinische Pädiatrie 2008. in German. (submitted)

22. Duijkeren E, van Wannet WJB, Houwers DJ, van Pelt W. Serotype and phage type distribution of Salmonella strains isolated from humans, cattle, pigs and chickens in The Netherlands from 1984-2001. J Clin Microbiol. 2002:40:39803985.

23. Hald T, Vose D, Wegener HC, Koupeev T. A bayesian approach to quantify the contribution of animal-food sources to human salmonellosis. Risk Analysis. 2004;24, 251-65.

24. Valkenburgh $S$, van Oosterom $R$, Stenvers D, Aalten M, Braks M, Schimmer B, et al. Zoonoses and zoonotic agents in humans, food, animals and feed in the Netherlands 2003-2006. RIVM-rapportnummer:330152001; 2007.

25. Bradley T, Angulo FJ, Raiti P. Association of Reptilian and Amphibian Veterinarians guidelines for reducing risk of transmission of Salmonella spp from reptiles to humans. J Am Vet Med Assoc. 1998;213(1):51-2.

This article was published on 12 June 2008.

Citation style for this article: Editorial team, Bertrand S, Rimhanen-Finne R, Weill FX, Rabsch W, Thornton L, Perevoscikovs J, van Pelt W, Heck M. Salmonella infections associated with reptiles: the current situation in Europe. Euro Surveill. 2008;13(24):pii=18902. Available online: http://www.eurosurveillance.org/ViewArticle. aspx?ArticleId $=18902$ 